San Jose State University

SJSU ScholarWorks

Master's Projects

Master's Theses and Graduate Research

$12-1-2006$

\title{
The Cost of Negative Perceptions of the Work Environment Among Intermediate Intensive Care Unit Nurses
}

Joselyn Peralta

San Jose State University

Follow this and additional works at: https://scholarworks.sjsu.edu/etd_projects

Part of the Critical Care Nursing Commons

\section{Recommended Citation}

Peralta, Joselyn, "The Cost of Negative Perceptions of the Work Environment Among Intermediate Intensive Care Unit Nurses" (2006). Master's Projects. 803.

DOI: https://doi.org/10.31979/etd.j4p4-b5xa

https://scholarworks.sjsu.edu/etd_projects/803

This Master's Project is brought to you for free and open access by the Master's Theses and Graduate Research at SJSU ScholarWorks. It has been accepted for inclusion in Master's Projects by an authorized administrator of SJSU ScholarWorks. For more information, please contact scholarworks@sjsu.edu. 


\section{SAN JOSE STATE UNIVERSITY \\ SCHOOL OF NURSING}

MASTER'S PROGRAM PROJECT OPTION (PLAN B)

PROJECT SIGNATURE FORM

STUDENT NAME

Josayn Parmuta

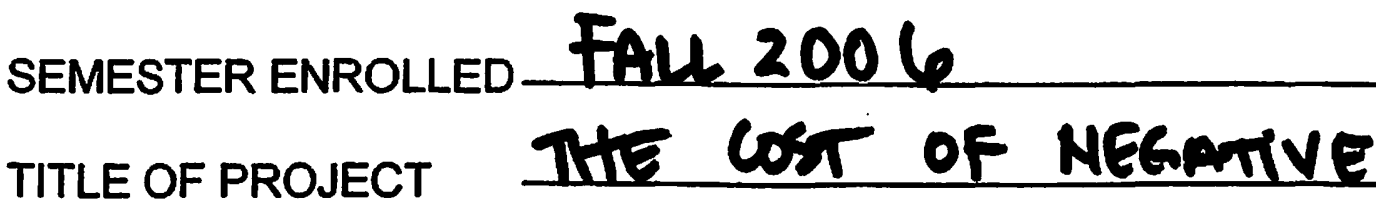

PERCETIONS OF THE WORK ENYIRONMENT

AMONG WTERMEDIATE INTENSIVE CARE UNIT NURSES

NAME OF JOURNAL NURSiNG ECONOMics

The project and manuscript have been successfully completed and meet the standards of the School of Nursing at San Jose State University. The project demonstrates the application of professional knowledge, clinical expertise, and scholarly thinking. An abstract of the project and two copies of the manuscript are attached.

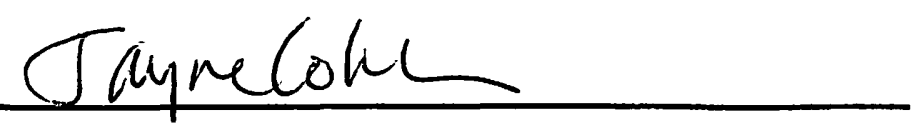

ADVISOR'S SIGNATURE

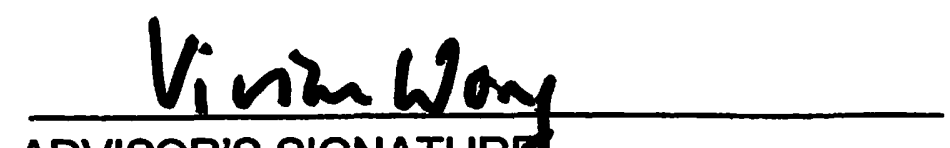

ADVISOR'S SIGNATURE;

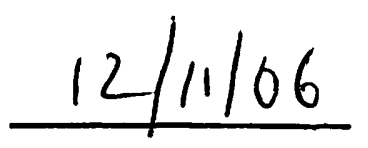

DATE

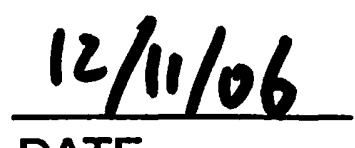

DATE

Please submit this form to the Graduate Coordinator. Attach abstract, two copies of the manuscript, and documentation of submission to the journal (i.e., postal receipt). 
The Cost of Negative Perceptions of the Work Environment Among Intermediate Intensive Care Unit Nurses

\begin{abstract}
This descriptive study assessed the perceptions of the work environment and the retention plans among registered nurses (RNs) who worked in the Intermediate Intensive Care Unit at a tertiary university hospital. Results from the Moos Work Environment Scale found that nurses perceived high levels of work pressure and low levels of clarity, coworker cohesion, and supervisor support. Results indicated that the intent to leave the unit was dependent on the nurses having other options in nursing, desiring further education, an undesirable scheduling process and unsafe patient care. The direct and indirect costs to hospitals could be offset by developing strategies to enhance the work environment, therefore increasing $\mathrm{RN}$ retention.
\end{abstract}


The Cost of Negative Perceptions of the Work Environment

Among Intermediate Intensive Care Unit Nurses

Joselyn Peralta, RN, MS

San José State University

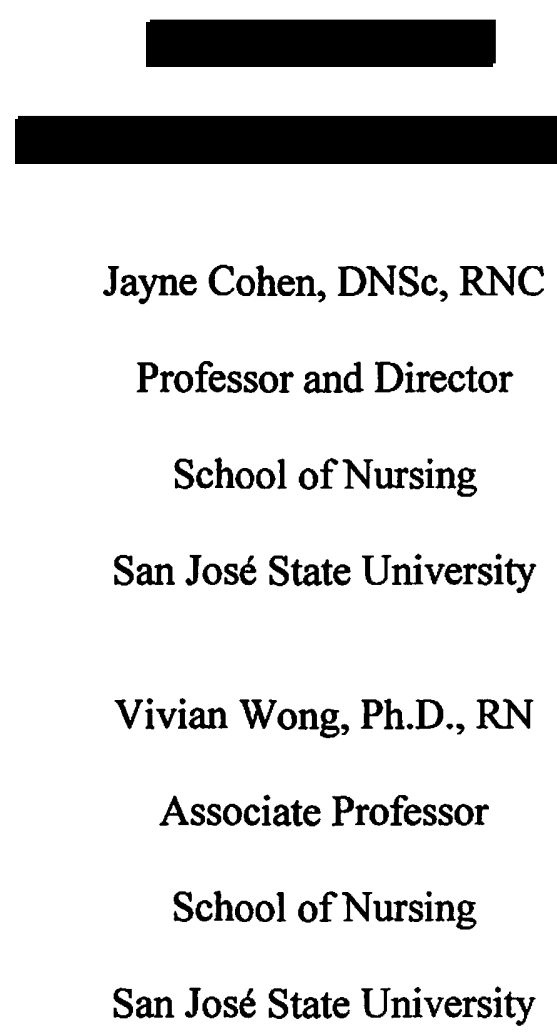

About the Authors:

Joselyn Peralta, MS, RN, is currently working at Stanford University Hospital in Northern California.

Dr. Jayne Cohen is a Professor and Director of the School of Nursing at San José State University, in San José, California.

Dr. Vivian Wong is an Associate Professor in the School of Nursing at San José State University, in San José, California. 


\begin{abstract}
This descriptive study assessed the perceptions of the work environment and the retention plans among registered nurses ( $\mathrm{RNs}$ ) who worked in the Intermediate Intensive Care Unit at a tertiary university hospital. Results from the Moos Work Environment Scale found that nurses perceived high levels of work pressure and low levels of clarity, coworker cohesion, and supervisor support. Results indicated that the intent to leave the unit was dependent on the nurses having other options in nursing, desiring further education, an undesirable scheduling process and unsafe patient care. The direct and indirect costs to hospitals could be offset by developing strategies to enhance the work environment, therefore increasing $\mathrm{RN}$ retention.
\end{abstract}


The Cost of Negative Perceptions of the Work Environment Among Intermediate Intensive Care Unit Nurses

The critical shortage of registered nurses (RNs) has forced institutions to direct much of their spending not only to recruiting but also towards retaining nurses. The average national turnover rate for hospital nurses is $21 \%$ per year with the highest turnover occurring in intensive care units, at $26 \%$ (HSM, 2002). The cost of replacing a nurse in a medical-surgical unit ranges from $\$ 10,000$ up to $\$ 92,442$ according to Johnson and Buelow (2003) and Colosi (2002). The cost of replacing a specialty nurse is even higher, as much as $\$ 145,000$ (Colosi, 2002). In an effort to enhance retention, some healthcare organizations have increased salaries to attract and retain nurses, whereas others have offered sign-on bonuses. These incentives may appear initially to be appropriate for attracting nurses and improving retention, but they fail to address some of the most powerful influences on job satisfaction and job retention, that is, the work environment. Aspects of the work environment, which have been examined in previous studies, have demonstrated positive correlations with job satisfaction and nursing retention (Joshua-Amadi, 2003; McNeese-Smith, 1999; Stordeur, Vandenberghe \& D'hoore, 2000). Work environmental factors include relationships among nurses and between nurses and their supervisors, significant work stressors (e.g., patient overload), and job satisfiers (e.g., flexibility of scheduling) in the workplace, as well as organizational support. According to Moos' (1994b), the major components of the work environment are involvement, coworker cohesion, supervisor support, autonomy, task orientation, work pressure, clarity, managerial control, innovation, and physical comfort. 


\section{Literature Review}

High turnover is a significant problem in many hospitals commonly due to low staff morale and low job satisfaction. The cost of nursing turnover includes direct and indirect costs related to advertising and interviewing, overtime, temporary replacement costs for per diem nurses, increase use of traveling nurses, terminal payouts and loss of productivity. The cost of lost productivity ranged from $\$ 5,235$ to $\$ 16,102$ (Waldman, Kelly, Arora, \& Smith, 2004). The Advisory Board Company (2000) reported that the cost of nurse turnover is largely due to the loss in productivity associated with acquiring new hires. They suggested that $21 \%$ of the cost is for direct hiring expenses. The other $79 \%$ is associated with productivity including a $15 \%$ loss during vacancy of the position, a $4 \%$ loss during departure, and a $81 \%$ loss while the new employee becomes fully productive.

The nursing literature indicates that work stress is among the most common and strongest predictors of job satisfaction for nurses, and that work stress is a precursor of intent to leave a position. In fact, recent literature suggests that nurses leave their places of employment because of high work stress. For example, Strachota, Normandin, O’Brien, Clary, and Krukow (2003) found that nurses left the workplace due to the stress associated with having sicker patients, insufficient staff, work overload, unpaid overtime, long shifts, and unsocial working hours (e.g., working weekends and holidays). According to McNeese-Smith (1999), the factors in the warkplace that contribute to work stress are heavy patient loads, rising patient acuity, too few staff members, job exhaustion, and fear of making a mistake. Aiken, Clarke, Sloane, Sochalski, and Silber (2002) supported this finding by noting that nurses with greater patient loads were likely to experience greater emotional exhaustion, burnout, and job dissatisfaction compared to nurses with smaller patient loads. Joshua-Amadi (2003) found that nurses felt overwhelmed 
beçause of insufficient staff and sicker patients, and that the reasons nurses left the unit included low pay, belief that no one cared about them, a poor work environment, decline of quality of care, and a constant feeling of tension. A number of studies assessed nurses' perceptions of their work environment in various nursing units (Hays, Mannahan, Duaderes, and Wallace, 2006; Hayhurst, Saylor, and Stuenkel, 2005; Kotzer, Koepping, and LeDuc, 2006). Hays, et al (2006) found that the most frequent stressors among intensive care nurses were short staffing and issues concerning patient families. Hayhurst et al. (2005) found that nurses in an acute care hospital who left their unit had more negative perceptions of their work environment than did those who stayed. These negative perceptions included low peer cohesion, lack of supervisor support and autonomy, and excessive work pressure. This suggests that negative perceptions of the work environment may potentially lead to higher nursing turnover.

Kotzer, et al. (2006) utilized Moos' Work Environment Scale (WES) to evaluate the real (current) and ideal (preferred) perceptions among acute care pediatric nurses. Findings concluded that, overall, nurses were satisfied with their work environment. The nurses perceived high levels of involvement, peer cohesion, supervisor support, autonomy, task orientation (e.g., emphasis on good planning, efficiency, and getting the job done), clarity, and managerial control. These findings suggest that nurses enjoyed their jobs and that their nurse managers were supportive and collaborative.

Conversely, factors in the work environment which have been shown to satisfy nurses are positive relationships with nursing peers, flexible schedules, desirable benefits, adequate staffing levels, and positive relationships with physicians. Price (2002) studied job satisfaction among nurses in an acute medical and surgical unit, and found that $58 \%$ were generally satisfied with their jobs, and that the major satisfiers included peers, annual leave, and hours worked. Lacey 
(2003) surveyed nurses in North Carolina and found that the top five reasons that respondents stayed in the workplace were good mentors and colleagues, satisfactory pay, desirable benefits, flexible scheduling, and positive relationships with physicians.

The importance of having managers with a favorable leadership style has been widely known to positively influence job satisfaction and retention. According to the American Organization of Nurse Executives (AONE), nursing leadership is one of the key factors for creating an excellent work environment and promoting nurse retention (Runy, 2005). Leadership styles that focused on shared governance, autonomy, communication, group cohesion, and empowerment of nurses have reportedly been associated with low turnover. An early study by Volk and Lucas (1991), which focused on managerial styles, found that a participative leadership style was associated with lower turnover, compared to an authoritarian leadership style. Later studies, such as that conducted by Fisher, Hinson, and Deets (1994), found that nurses tended to stay in a place of employment when nurse managers encouraged staff to participate in decision making and when the managers adopted a participative model. Stordeur et al. (2000) supported these findings and suggested that managers who encouraged staff collaboration and decisionmaking tended to create a more positive climate among the nursing team. Moreover, nurse managers who were open and extroverted and who encouraged autonomy, group cohesion, and staff empowerment promoted nurse retention (Force, 2005). To improve the work environment, nurse executives and nurse managers must establish an environment that supports professional practice (Runy, 2005).

It is important to identify the factors in the work environment that affect job satisfaction. The literature demonstrated that factors in the work environment influence job satisfaction ultimately affecting retention; therefore, it is important for healthcare organizations to develop 
solutions to improve job satisfaction and thereby help to retain the most qualified and experienced RNs.

Purpose

The purpose of this exploratory study was to assess the work environment and career plans of nurses employed in the intermediate intensive care unit (IICU) at a tertiary university hospital in Northern California. The questions addressed were: (a) What are the perceptions of the work environment among IICU nurses? and (b) What is the relationship between nurses' perceptions of the workplace and their plans to remain in or leave the unit?

The IICU is a cardiac monitored, adult, 40 -bed unit. Nurses in the IICU work with many patients who require continuous and specialized care. It is a fast-paced environment with a high turnover of patients. Although the IICU houses a primary population of postoperative cardiothoracic, vascular, and transplant surgery patients, it also includes cardiology, general surgery, trauma, and general medicine. The patients in this unit require cardiac monitoring, major wound care, and respiratory care above the level of the general medical-surgical unit but below the level of ICU care.

\section{Conceptual Framework}

This study utilized the Conceptual Model of Organization and Personal Factors and Outcomes developed by Moos (1994b). His model integrates three aspects of the workplace including: (a) Human relations, which refers to the quality of the relationship between employees and supervisors; (b) The sociotechnical characteristics, which encompass matters such as stressors involved in the work performed by employees and how work groups in the organization are organized; and (c) The social information processing orientation, which represents the employees' perceptions of their work environments. The model suggests that work stressors and 
coping responses are an outcome of the relationship between personal factors and organizational systems. In addition, the relationship between personal factors, organizational systems, and work stressors affect coping responses and employee and organizational outcomes, and ultimately impact work morale, performance, and quality of patient care.

\section{Sample}

The target population of 80 consisted of IICU staff RNs employed full time, part time, and on a per-diem basis. These nurses who were working in a tertiary university hospital in Northern California were directly involved in patient care. Managers, supervisors, clinical nurse specialists, staff development nurses, and nurse travelers were excluded from the study. The final sample consisted of 31 subjects, representing a $38.8 \%$ return rate.

\section{Procedure}

The study was conducted after receiving approval from the Institutional Review Boards (IRBs) of both the hospital and the university. Fliers advertising the study were placed around the unit. Data collection packets were then put in all IICU RNs mailboxes. Each packet included the following items: (a) a cover letter; (b) a consent form; (c) three instruments; and (d) a stamped, self-addressed envelope for return of the instruments.

\section{Timeline}

The participants were asked to complete the survey while off duty and to return their responses by mail within 3 weeks of the initial distribution. They were asked not to write their names on any of the forms in order to keep their identities confidential. The approximate time to complete the tools was 30 minutes.

Packets received from each participant were coded to ensure that each questionnaire corresponded to one individual. The survey data were kept strictly confidential, housed in a 
locked filing cabinet. Only the researchers and the consulting statistician had access to the raw data.

Instruments

Three data-gathering instruments were used. The demographic tool was used to gather information regarding the participants' gender, age group, race or ethnicity, marital status, years worked as an RN, years worked in the IICU, current status in the IICU, shift work, and highest degrees achieved in nursing. The retention questionnaire gathered information on the reasons IICU nurses decided to leave or remain in their current position within a year. The questions included:

1. How likely are you to leave the IICU in the next year?

2. If you choose to stay on at this unit, what are the main reasons for your decision?

3. If you choose to leave this unit, what are the main reasons for your decision?

The Moos Work Environment Scale (WES) (form R) (Moos, 1994a) was used to measure perceptions of the work environment. This questionnaire consists of 90 true/false questions incorporating 10 subscales. The WES subscales and their definitions are described in Table 1. Each of these subscales is grouped into three underlying dimensions: personal growth, relationships, and system maintenance and change.

The personal growth dimension pertains to the emphasis on being independent, getting the job done, and meeting job demands. The relationships dimension examines the extent to which employees are concerned with their commitment to their jobs, how friendly the employees are, and how supportive they are of each other. Systems maintenance and change is concerned with the emphasis on rules and policies within the work setting, as well as variety and innovation 
and the pleasantness of the physical setting. The validity and reliability of the WES have been well documented (Flarey, 1991, 1993; Moos, 1994b).

Sample Characteristics

The majority of respondents were female (77.4\%), between the ages of 26 and 30 (29.0\%), and married (61.3\%). The majority had fewer than 10 years of experience as a RN (64.6\%), and 5 or fewer years in the IICU (54.8\%). In addition, the majority worked full time (67.7\%), worked 12 hours night shifts (48.4\%), and had a bachelor's degrees in nursing (71.0\%). The subjects were culturally and ethnically diverse, with more than half being of Asian and Pacific Islander descent (54.8\%), and Caucasians composing more than one third of the respondents (35.5\%). The remaining subjects consisted of Latinos (3.2\%), African Americans (3.2\%), and some from other or unknown backgrounds (3.2\%).

Data Analysis

The aggregate means on each subscale were calculated to determine the perceptions of the work environment. The $t$-test and Analysis of Variance (ANOVA) were used to determine the relationships between the WES subscales and the demographic data.

Results

The IICU nurses rated the following subscales to be above average: (a) Work Pressure (e.g., the extent to which high work demands and time pressure dominated the job milieu); (b) Involvement (e.g., the degree to which employees were concerned about and committed to their jobs); (c) Task Orientation (e.g., the emphasis on good planning, efficiency, and getting the job done); (d) Control (e.g., the extent to which management used rules and procedures to keep employees under control); and (e) Physical Comfort (e.g., the extent to which the physical surroundings contributed to a pleasant work environment). The subscales considered to be 
average included: (a) Autonomy (e.g., the extent to which employees were encouraged to be selfsufficient and to make their own decisions) and (b) Innovation (e.g., the degree of emphasis on variety, change, and new approaches). Considered below average was Clarity (e.g., the extent to which employees knew what to expect in their daily routines and how explicitly rules and policies were communicated). The subscale that ranked well below average was Supervisor Support (e.g., the degree to which management was supportive of employees and encouraged them to be supportive of one another). Peer Cohesion (e.g., the degree to which employees were friendly and supportive of one another) was considerably below average. These results are depicted in Table 2.

The majority of respondents (61.3\%) indicated that they planned on staying in the unit for at least one year. Among those who planned to stay, their principal reasons for staying were positive relationships with nursing peers, flexible scheduling, caring of patients with a variety of illnesses, and the familiarity with the work environment. More than a third (33.3\%) of the sample indicated that they were likely to leave their place of employment within one year. Among those who said they were likely to leave, the top four reasons given were pursuing other options in nursing, followed by furthering education, obtaining better scheduling, and finding an environment where they would not encounter unsafe patient care. Less common reasons for leaving were heavy workloads and lack of support. Among the respondents who indicated that they planned to leave the unit, the majority of them were between the ages of 26 and 30 (50\%). Findings in this study did not reveal any statistically significant differences between nurses' perceptions of the workplace and their plans to remain or leave the unit. 


\section{Limitations}

The study utilized a small convenience sample collected from a single unit at one tertiary university hospital. The participants in this study may not be representative of nurses in other institutions or nursing departments. Most respondents were young nurses from Asian and Pacific Island cultures. The ethnic diversity of this sample may not represent the population in other areas. Participation was voluntary; therefore, nurses with negative perceptions of their work environment may have been more motivated to complete the packets. Conversely, those who were satisfied with their work environment may have been less compelled to complete the survey, thus skewing the results. It is important to note that during the study, a new computer charting system had been recently installed and the hospital was in the process of applying for Magnet hospital status. These factors may have contributed to respondents expressing high levels of work pressure.

\section{Discussion}

The findings suggest that IICU nurses, for the most part, had a positive perception of their work environment. However, they indicated high levels of Work Pressure and low levels of Clarity, Peer Cohesion, and Supervisor Support. These IICU nurses' decision to stay was based on having camaraderie among peers and flexible scheduling. These findings are consistent with those of Price (2002) and Lacey (2003), whose studies concluded that nursing peers and scheduling were among the major satisfiers in nurses' work.

The current study found that the nurses most likely to leave were younger (ages 26-35), and that their principal reason for leaving was to seek other opportunities in nursing There are abundant opportunities in nursing today, enabling RNs to move easily from one position to 
another. Negative perceptions of the work environment might serve only as a catalyst to leave a position.

In order to reduce the costs associated with high turnover rates, to keep experienced nurses who can provide quality patient care, and to thereby minimize the current nursing shortage, nurse managers should address workplace factors important to nurses on their units. Nurse managers can develop successful strategies and solutions to the issues that nurses feel negatively affect their work environment. Constant change and mounting rules and regulations, a disorganized work environment, and ambiguous responsibilities and expectations of nurses decrease clarity in the workplace. Therefore, it is important for nurse managers to clearly define their expectations of nurses and to successfully communicate rules, procedures, and policies to the nursing staff. Leadership begins at the top and therefore it is essential for the Chief Nursing Officer of the organization to support their unit managers with professional development opportunities and financial resources. This will enable the nurse managers to share the organization's vision and mission with the nursing staff.

Supervisor support is equally critical in improving nurses' perceptions. Studies have shown that nurse managers who supported and practiced a shared governance model promoted nurse retention (Stordeur et al., 2000). It would be essential for nurse managers to develop a work culture that supports autonomy and promotes nursing leadership skills, communication, peer cohesion, and education. In addition, nurse managers can develop the skills to be approachable, accessible, and willing to listen to nurses' concerns and to develop collaborative solutions. It is also essential for nurse managers to support their nurses by justifying the need for additional staffing when the patient acuity level is high, and to allow realistic time to complete comprehensive professional nursing care. 
A feeling of cohesion, a sense of family, and the ability to talk freely with managers on a personal level all have a positive impact on job satisfaction and nurse retention. Nurses who believed that they had a positive impact on their organization and who felt rewarded stayed in the organization (Manion, 2004). It is vital for the organization to allow adequate time for communication among nurses as well as with managers, to get nurses together to talk openly and freely about issues in the workplace, to take time to appreciate the nurses for a job well done, and to make the nursing staff feel that they are important to the organization and that they do make a difference in their workplace.

The current shortage of nurses and the anticipated continued worsening of the shortage encourage all concerned to work to increase nurse retention by improving the work environment. Poor nurse retention not only increases direct and indirect costs, but it also deteriorates the job milieu, thereby increasing stress for the nurses who remain. Nurse managers are responsible for cultivating positive working environments that will ultimately increase nurse retention and achieve the main goal of providing safe patient care. In turn, the nursing staff must accept responsibility for continually shaping their work environment in positive ways.

This study identified several negative factors in the work environment of the IICU, setting the stage to devise solutions that will improve the unit's overall functioning. This translates directly to significant cost savings. We recommend further studies on this topic with larger samples in multiple settings in different geographical areas.

The cost for an organization to replace a registered nurse is very high. Replacing a medical-surgical nurse costing approximately $\$ 92,000$ would cost the hospital nearly $\$ 1$ million if all of the IICU nurses with the intent to resign from their jobs actually leave. Therefore, it would be prudent for nurse managers and the healthcare organizations to examine their practices 
that affect the nursing work environment in order to develop solutions to satisfy and retain nurses and ultimately improve the quality of patient care. 
Table 1

WES Subscales and Definitions

\begin{tabular}{|c|c|c|}
\hline Dimensions & Subscales & Definitions \\
\hline \multirow[t]{3}{*}{ Relationship dimensions } & Involvement & $\begin{array}{l}\text { The extent to which employees are concerned } \\
\text { about and committed to their jobs }\end{array}$ \\
\hline & Coworker cohesion & $\begin{array}{l}\text { How much employees are friendly and supportive } \\
\text { of one another }\end{array}$ \\
\hline & Supervisor support & $\begin{array}{l}\text { The extent to which management is supportive of } \\
\text { employees and encourages employees to be } \\
\text { supportive of one another }\end{array}$ \\
\hline \multirow[t]{3}{*}{ Personal growth dimensions } & Autonomy & $\begin{array}{l}\text { How much employees are encouraged to be self- } \\
\text { sufficient and to make their own decisions }\end{array}$ \\
\hline & Task orientation & $\begin{array}{l}\text { The emphasis on good planning, efficiency, and } \\
\text { getting the job done }\end{array}$ \\
\hline & Work pressure & $\begin{array}{l}\text { The degree to which high work demands and time } \\
\text { pressure dominate the job milieu }\end{array}$ \\
\hline \multirow[t]{4}{*}{$\begin{array}{l}\text { System maintenance and } \\
\text { chąnge dimensions }\end{array}$} & Clarity & $\begin{array}{l}\text { Whether employees know what to expect in their } \\
\text { daily routine and how explicitly rules and policies } \\
\text { are communicated }\end{array}$ \\
\hline & Managerial control & $\begin{array}{l}\text { How much management uses rules and } \\
\text { procedures to keep employees under control }\end{array}$ \\
\hline & Innovation & $\begin{array}{l}\text { The emphasis on variety, change, and new } \\
\text { approaches }\end{array}$ \\
\hline & Physical comfort & $\begin{array}{l}\text { The extent to which the physical surroundings } \\
\text { contribute to a pleasant work environment }\end{array}$ \\
\hline
\end{tabular}

Note. Copied with Moos' permission (1994b, p. 1). 
Table 2

Subscale Perceptions and Means $(N=31)$

\begin{tabular}{llll}
\hline \multicolumn{1}{c}{ Subscale } & \multicolumn{1}{c}{ Finding } & $M$ & $S D$ \\
\hline Work pressure & Above average & 7.13 & 1.73 \\
Involvement & Above average & 6.87 & 1.61 \\
Task orientation & Above average & 6.68 & 1.77 \\
Control & Above average & 5.87 & 1.74 \\
Physical comfort & Above average & 5.55 & 2.22 \\
Autonomy & Average & 5.18 & 1.87 \\
Innovation & Average & 4.87 & 2.28 \\
Clarity & Below average & 5.32 & 2.09 \\
Supervisor support & Well below average & 4.39 & 2.46 \\
Peer cohesion & $\begin{array}{l}\text { Considerably } \\
\text { below average }\end{array}$ & 3.97 & 1.68 \\
\hline
\end{tabular}




\section{References}

Advisory Board Company.(2000). Reversing the flight of talent. (Executive Briefing Vol 1). Washington, DC: Nursing Executive Center.

Aiken, L. H., Clarke, S. P., Sloane, D. M., Sochalski, J., \& Silber, J. H. (2002). Hospital nurse staffing and patient mortality, nurse burnout, and job satisfaction. The Journal of the American Medical Association, 288(16), 1987-1993.

Colosi, ML. Rules of engagement for the nursing shortage: more registered nurses on staff leads to lower hospital costs. JONA's Healthcare Law, Ethics, and Regulation. (2002); 4(3): 5054.

Fisher, M. L., Hinson, N., \& Deets, C. (1994). Selected predictors of registered nurses' intent to stay. Journal of Advanced Nursing, 20(5), 950-957.

Flarey, D. L. (1991). The social climate scale: A tool for organizational change and development. Journal of Nursing Administration, 21(4), 37-44.

Flarey, D. L. (1993). The social climate of work environments. Journal of Nursing Administration, 23(6), 9-15.

Force M. V. (2005). The relationship between effective nurse managers and nursing retention. Journal of Nursing Administration, 35(7/8), 336-341.

Hayhurst, A., Saylor, C., \& Stuenkel, D. (2005). Work environmental factors and retention of nurses. Journal of Nursing Care Quality, 20, 283-288.

Hays, M. A., All, A. C., Mannahan, C., Duaderes, E., \& Wallace, D. (2006). Reported stressors and ways of coping utilized by intensive care unit nurses. Dimensions of Critical Care Nursing, 25(4), 185-193. 
HSM Group, Ltd., The (2002). Acute care hospital survey of RN vacancy and turnover rates in 2000. Journal of Nursing Administration, 32, 437-439

Johnson, J. E., \& Buelow, J. R. (2003). Providing staff feedback to nurse managers using internal resources. Journal of Nursing Administration, 33(7/8), 391-396

Joshua-Amadi, M. (2003). Recruitment and retention in the NHS: A study in motivation. Nursing Management, 12(9), 24-32.

Kotzer, A. M., Koepping, D. M., \& LeDuc, K. (2006). Perceived nursing work environment of acute care pediatric nurses. Pediatric Nursing, 32(4), 327-331.

Lacey, L. M. (2003). Called into question: What nurses want. Nurse Management, 34, 25-26. Manion, J. (2004). Nurture a culture of retention. Nurse Manager, 35(8), 49-51.

McNeese-Smith, D. K. (1999). A content analysis of staff nurse descriptions of job satisfaction and dissatisfaction. Journal of Advanced Nursing, 29(6), 1332-1341.

Moos, R. H. (1994a). A work environment scale (form R) (3 $3^{\text {rd }}$ ed.). [Psychological Instrument]. Palo Alto, CA: Consulting Psychologist Press.

Moos, R. H. (1994b). Work environment scale manual: Development, applications, and research ( $3^{\text {rd }}$ ed.). Palo Alto, CA: Consulting Psychologist Press.

Price, M. (2002). Jobs satisfaction of registered nurses working in an acute hospital. British Journal of Nursing, 11(4), 275-280.

Runy, A. (2005). Nurse retention: An executive's guide to keeping one of your hospital's most valuable resources. Nursing Organization Alliance. Retrieved November 10, 2006, from http://www.hhnmag.com/hhnmag_app/jsp/article

Stordeur, S., Vandenberghe, C., \& D'hoore, W. (2000). Leadership styles across hierarchical levels in nursing departments. Nursing Research, 49(1), 37-43. 
Strachota, E., Normandin, P., O'Brien, N., Clary, M., \& Krukow, B. (2003). Reasons registered nurses leave or change employment status. Journal of Nursing Administration, 33(2), 111-117.

Volk, M. C., \& Lucas, M. D. (1991). Relationship of management style and anticipated turnover. Dimensions of Critical Care Nursing, 10(1), 35-40.

Waldman, J. D., Kelly, F., Arora, S., \& Smith, H.L. (2004). The shocking cost of turnover in health care. Health Care Management Review, 29(1), 2-7. 


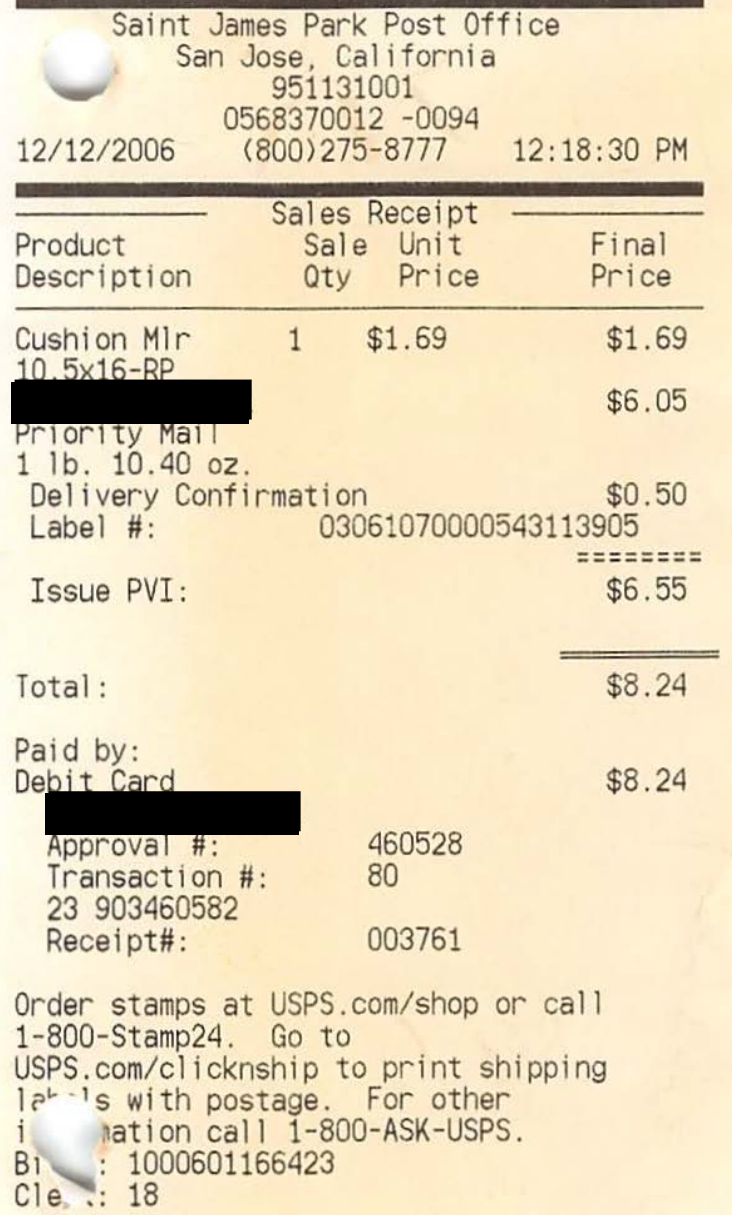

All sales final on stamps and postage. Refunds for guaranteed services only. Thank you for your business. Customer Copy 